\title{
Summary
}

1. Considerable departures from the classical methods of treatment are now possible in trachoma. The time honoured copper sulphate stick has no place in present day therapy.

2. Expression and the local use of sulphacetamide can in themselves bring about a clinical cure of trachoma.

Valuable supplementary measures are general sulphonamide therapy, local application of saturated solution of quinine bisulphate, mercury perchloride $\frac{1}{2}-2$ per cent. in glycerine; and subconjunctival injections of trachocid.

4. Modern therapy cuts drastically the period of infectivity and the duration of treatment.

\section{A CASE OF MUSTARD GAS KERATITIS TREATED WITH CURETTAGE OF THE CORNEA FOR THE REMOVAL OF A BAND-SHAPED CRYSTALLINE DEPOSIT*}

B̀Y

HUMPHREY NEAME

LONDON

Owing to the fact that the cornea of severe cases of mustard gas keratitis is liable to recurring ulceration, it has become customary to regard such corneae as unsuitable for operation. The following case seems worth recording as an example of the fallacy of the opinion mentioned-above.

Fréd H., aged 56 years, was fitted with contact lenses in 1939 on account of progressive deterioration of vision. In January, 1940, with contact lenses R.V. $=6 / 24,6 / 18$ (1) ; L.V. 6/60. In August, 1940, ditto, R.V. 6/18, L.V/6/60. In April, 1941, ditto, R.V. 6/18, L.V. less than $6 / 60$. In July, 1941 , ditto, R.V. $6 / 24$, L.V. $3 / 60$. In November, 1942, ditto, R.V. 6/24. The left cornea showed a transverse band across and below the pupillary area of the cornea composed of a superficial deposit of glistening crystalline appearance completely obstructing the vision.

On November 27, 1942, curettage of the band-shaped opacity was performed under local anaesthesia. Healing of the cornea was uneventful. In May, 1943, with contact lenses, R.V.=6/18, L.V. $=6 / 60$, and in November, 1944, R.V. $=6 / 24,6 / 18$ (3), L.V.= $6 / 36$. The patient was very appreciative of the improvement in the vision of the left eye.

* Received for públication December 23, 1944, 